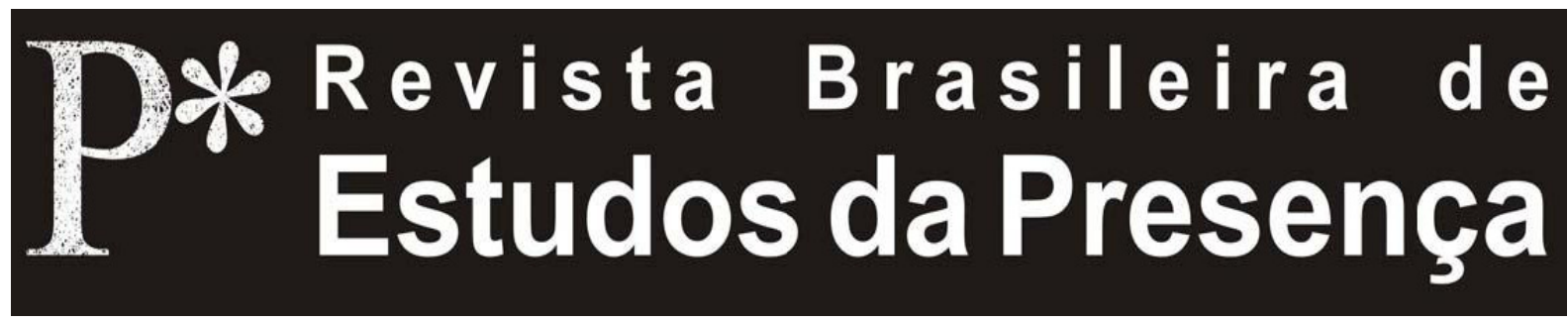

DOI - http://dx.doi.org/10.1590/2237-266026492

ISSN 2237-2660

\title{
O Estudo das Práticas Perfiormativas na Perspectiva de uma Antropologia da Estética
}

\author{
Laure Garrabé \\ Maison des Sciences de l'Homme Paris Nord - MSH, Saint-Denis, França \\ Universidade Federal de Santa Maria - UFSM, Santa Maria, RS, Brasil
}

RESUMO - O Estudo das Práticas Performativas na Perspectiva de uma Antropologia da Estética - Este texto propõe uma contribuição ao estudo das práticas performativas a partir de uma apreensão antropológica na qual a estética, entendida como aisthesis, se estabelece como hermenêutica das formas de socialização e de individuação em ato no fenômeno estudado. Apresenta-se um aparelho epistemológico no qual as noções de ritmo e de relação, átomos irredutíveis de toda forma de estética, teriam valor paradigmático. Através delas, discute-se a possibilidade de apreender os modos de produção, de recepção e de apropriação, caracterizando formas de práxis cujos graus de construção (da ação, da experiência e dos imaginários) e de intencionalidade são as variáveis que determinam a singularidade e a inserção dessas formas em dispositivos (da arte) socialmente reconhecidos.

Palavras-chave: Antropologia. Estética. Práxis. Técnica. Práticas Espetaculares.

ABSTRACT - The Study of Performing Arts Through the Prism of an Anthropology of Aesthetics - This text proposes a contribution to the study of performing practices with an anthropological approach where aesthetics, understood as aisthesis, stands as a hermeneutic reading of the forms of socialization and individuation acting in the phenomenon studied. It presents an epistemological apparatus in which notions of rhythm and relation, irreducible atoms of any form of aisthesis, have a paradigmatic value. Through them, we could read the modes of production, reception, and appropriation characterizing forms of praxis whose degrees of construction (of action, experience and imagination) and intentionality, are the variables determining their singularity and their insertion in socially constructed (artistic) devices.

Keywords: Anthropology. Aesthetics. Praxis. Technics. Performing Arts.

RÉSUMÉ - L'Étude des Pratiques Performatives au Prisme d'une Anthropologie de l'Esthétique - Ce texte propose une contribution à l'étude des pratiques performatives à partir d'une approche anthropologique où l'esthétique, entendue comme aisthesis, s'établit en tant que grille de lecture des formes de socialisation et d'individuation à l'œuvre dans le phénomène étudié. Il présente un appareil épistémologique où les notions de rythme et de relation, atomes irréductibles de toute forme d'aisthesis, auraient une valeur paradigmatique. À travers elles, nous pourrions appréhender les modes de production, réception, et d'appropriation caractérisant des formes de praxis dont les degrés de construction (de l'action, de l'expérience et des imaginaires) et d'intentionnalité, sont les variables déterminant leur singularité et leur insertion dans des dispositifs (de l'art) socialement construits.

Mots-clés: Anthropologie. Esthétique. Praxis. Technique. Pratiques Spectaculaires. 
Este texto ${ }^{1}$ propõe uma contribuição ao estudo das práticas performativas numa perspectiva antropológica, sendo elas apreendidas como práticas singulares de (de)socialização e de (des)individuação. Isso implica mais particularmente contribuir para uma certa antropologia da estética, na qual a estética só pode ser considerada no seu sentido etimológico grego de aisthesis, designando a percepção pelos cinco sentidos - o percepto - alterada pelas suas consequências mais ou menos imediatas - o afeto e o conceito (Deleuze; Guattari, 1991). A estética apreendida aqui reintroduz a práxis e o afeto como pontos da articulação da análise, similarmente à proposta de experiência estética de Hans Robert Jauss (1978), numa abordagem que, de um lado, enraíza-se na tríade epistemológica fisio-psico-sociológica de Marcel Mauss e, de outro lado, supõe uma interdisciplinaridade menos por se ligar a diversos campos disciplinares (antropologia do corpo, antropologia das técnicas, filosofia, etnocenologia) que por tentar responder a certa exigência de totalidade. Trata-se de apreender os indivíduos psíquicos e coletivos nos seus modos de construir corporeidades diversas - técnicas corporais investidas de relações sensíveis variáveis e sempre específicas - a partir das quais elas se juntam na sucessividade do tempo e, através das quais, defendem suas identificações, sempre tensas entre suas singularidades e seus pertencimentos coletivos.

De fato, a análise das práticas corporais - inclusive as práticas ditas performativas e/ou espetaculares geralmente associadas ao mundo da arte - como conjunto de formas e ritmos concretos (vocais, gestuais ou imagéticos), apresenta o risco de cair na armadilha semiótica. As ciências da estética (história da arte, estética, filosofia e semiologia) ou do social (linguística, etnometodologia) reformaram várias vezes na história das ciências ${ }^{2}$ ou a distância entre o afeto e o conceito, ou francamente romperam com o percepto, aniquilando desse modo a validade do processo sensível nas produções humanas, ou seja, precisamente a geração de uma relação entre o sujeito percebendo e o objeto de sua atenção. Esse incidente tem a ver com os limites da linguagem, mas também com certa compulsão bem ocidental à "ontologização do real" (Schaeffer, 
2004, p. 28) e, consequentemente, à apreensão mecanicista da socialização humana. No entanto, para evitar toda atitude teórica arrogante e toda interpretação abusiva no estudo das práticas corporais, trata-se de retomar a noção - e não o conceito - de estética, muitas vezes reservada ao domínio filosófico ou das artes, às suas concretudes e funcionalidades. Melhor, à sua escala humana. Em seguida, convém observar a experiência sensível em ato através das negociações da expressão e da percepção (recepção incluída nesta última), exercidas ou experimentadas pelos indivíduos. A estética é assim centrada numa epistemologia da relação, entendida como fenômeno, agindo, formando, desformando e reformando os laços.

Assim concebida, a estética permite apreender todas as práticas corporais, mas ganha mais consistência ainda com as que exigem, para serem percebidas e produzidas, colocadas em ato na e pela cena, um sobrecusto da atenção cognitiva (Schaeffer, 2000). Essa noção, como veremos, traz a tona o que muda de uma prática corporal (uma técnica do corpo como montagem tradicional de séries de atos) para uma prática dita espetacular ou performativa. Nestas últimas, sejam elas artísticas - quer dizer reconhecidas dentro de dispositivos da arte (verbais e materiais) colocados à disposição de e reconhecidos por um conjunto sociocultural dado - ou não, os praticantes são precisamente experts da matéria e da negociação da experiência sensível, mas, também, cultivam a intenção de afetar o outro através dessas construções (corporais, instrumentais, afetivas). Porém, esse sobrecusto da atenção intervém também nas práticas corporais. Ele distingue práticas corporais de práticas performativas somente pelo grau de construção e de intencionalidade que o indivíduo ou o grupo injeta nas técnicas e nos códigos, determinando sua prática. O corpo, nesse caso, sendo simultaneamente o alvo e a fonte da percepção, retoma sua consistência de matéria trabalhada tanto fisiologicamente como afetivamente, sem, portanto, assimilar no indivíduo nem o que diz respeito a uma modelagem supostamente externa relativa à modelagem interna, de um lado; tampouco o que diz respeito a uma corporeidade originada de faculdades próprias a uma corporeidade adquirida por habitus, de outro lado. 
Uma prática se define pelo fato de ser repetida, experimentada e reconhecida coletivamente no seio de coletividades mais ou menos abrangentes. O grau de construção dos gestos, códigos e afetos, e sua repetição na sucessividade do tempo, participa assim da elaboração de sua singularidade: são, portanto, capazes de revelar as maneiras pelas quais os grupos sociais instrumentalizam suas produções estéticas para individualizar-se ou socializar-se dentro e fora do grupo. $\mathrm{O}$ Lume Teatro, a Sasha Waltz and Guests, um grupo de dança folclórica da Romênia, uma agremiação carnavalesca brasileira, ou até trabalhadores rurais nos morros da Martinica, constroem todos coletivamente formas de sociabilidades em torno de códigos e corporeidades (técnicas) que lhes permitem se identificar ou, ao contrário, se desligar, numa escala infinita de variações, das representações ou dos enunciados culturais nos quais exercem ou se expõem. Ao mesmo tempo, constroem o que poderíamos chamar de comunidade estética, sensível, e sua respectiva historicidade.

Ainda, apesar da confusão subsequente do uso da noção de performance na epistemologia dos estudos teatrais e coreográficos não anglo-saxões, tal como a etnocenologia ${ }^{3}$ apontou, consideramos as noções de performatividade e performativo como operatórias para um dos aspectos contido no radical perform: a potência de agir (puissance d'agir) é o que esse radical denota estritamente, qualificando os atos de linguagem e as corporeidades indissociavelmente atravessadas de variações fisiológicas e psíquicas. Essa puissance d'agir (uma das traduções francesas mais próximas do inglês agency, descrevendo a competência da performatividade) ${ }^{4}$, é o átomo irredutível do senso do verbo no francês antigo parformer - agir, mas também perfazer (parfaire) - que nós não possuímos mais em língua francesa, desde sua reelaboração em língua inglesa ${ }^{5}$ através da noção de performance. Hoje, a noção francesa usual de performance conservou sua conotação quantitativa (do sempre mais, o agir conotado pela perfetibilidade do parfaire), ao detrimento de sua consistência qualitativa (o agir como qualidade singular da ação). Contudo, o agir contido no performativo, pois se inscreve na ação (verbal 
ou gestual) e transforma de modo mais ou menos importante o contexto no qual ela acontece, é dotado de uma dimensão fundamentalmente política ${ }^{6}$, mas na medida em que poderia residir, como veremos, na repetição.

A partir de uma leitura política de Spinoza, Toni Negri (1982) faz uma distinção fundamental: o poder como potere, entendido como poder sobre e o poder como potentia, entendido como poder de, potência (puissance), quer dizer a capacidade ou a faculdade para realizar um ato, através do qual o sujeito atualiza suas potencialidades. É essa segunda dimensão do poder que denota a noção de performativo, uma denotação que fora trazida a luz por, entre outros, os linguistas Noam Chomsky e John L. Austin, e os antropólogos Judith Butler, Paul Gilroy e Homi K. Bhabha, trata-se, assim, dessa potencialidade política de emancipação do sujeito e de transformação do social. Essa dimensão política do performativo foi retida, contudo, sem ser chamada assim, por vários filósofos reformadores da estética. Entre eles, Jauss assinalava na sua conferência de 1972 a urgência em devolver à estética suas "[...] funções sociais [...] de normalização coletiva e de emancipação do sujeito" (1978, p. 172). Voltaremos ao assunto.

Essa dimensão política do performativo - essa força ativa transformadora do social - nos parece fundamental na apreensão das práticas corporais. O radical perform tem a ver com a acontecibilidade e sua pertinência erige-se assim na contingência gerada da desorganização potencial do social através da montagem e da realização de técnicas, que são também tecnologias do sensivel. É essencial tomar em conta diante da diversidade crescente dos gêneros e das formas ditas performativas, devido não somente à abertura das fronteiras e aos fenômenos diaspóricos mais ou menos duráveis, mas também à aceleração do desenvolvimento das tecnologias necessárias a sua difusão e a sua realização. Centrar a abordagem no agir socializante do grupo, o qual modela esse agir a partir de um corpus tecnológico instituindo-se nas práticas de expressão corporal - nas quais o corpo é simultaneamente o alvo e a fonte da percepção -, qual seja a forma de sociabilidade do grupo em questão, volta igualmente a questionar 
"[...] a parte fundadora de outrem na relação que todo homem nutre pelo mundo e, notadamente, na maneira pela qual seu corpo é socialmente construído" (Le Breton, 2004a, p. 14). Desse modo, a estética pode tornar-se novamente um projeto antropológico.

A tríade epistemológica estética, técnica e socialização, forjada assim, é, na realidade, o centro da obra que o etnólogo e estudioso da Pré-história André Leroi-Gourhan (1911-1986) perseguiu na linha direta das preocupações de Marcel Mauss com as técnicas do corpo.

\section{A Herança de um Programa}

Como filho espiritual e aluno de Mauss, André LeroiGourhan prorroga a famosa tríade epistemológica de "montagens psico-físio-sociológicas de séries de atos" (Mauss, 2001, p. 384) retomada incondicionalmente pelos Performance Studies teorizados por Richard Schechner (2001), pela Etnocenologia teorizada por Armindo Bião (2009) e Jean-Marie Pradier (2007), e mesmo pela Antropologia Teatral - projeto artístico e não disciplina acadêmica - teorizada por Eugenio Barba (2008). Entretanto, Leroi-Gourhan responde à exigência de totalidade tal como foi levantada por Mauss, introduzindo um pensamento da técnica (obras originalmente publicadas em 1964, 1965, 1968) articulado de maneira original à dimensão estética, então inédita. Pai do que chamamos na França de Antropologia Técnica ou Antropologia das Técnicas, LeroiGourhan $(1968$, p. 1817) reivindicava essa herança e a necessidade de uma abordagem interdisciplinar, reconhecida pelos seus pares e estudantes (Bromberger et al., 1986) - bem antes de ela ocupar nas ciências sociais o lugar que lhe consagramos hoje $^{7}$ - particularmente fértil para a reconstituição da evolução das técnicas como práticas de socialização e de criatividade singulares, num contexto sempre determinado.

Para ele, a tecnologia identificando uma prática continha precisamente a singularidade do que chamava a "vida étnica" (Leroi-Gourhan, 1968, p. 1820). Mas, é aqui que sua articulação entre técnica e estética é suscetível de enriquecer a apreensão das práticas corporais e espetaculares, pois ele 
se interessava mais particularmente, segundo uma fórmula de Bruno Karsenti, pelos modos específicos pelos quais o Homem, a partir de suas técnicas corporais, "se projetaria para fora no espaço comum do social" (Karsenti, 1998, p. 236-237). Sua concepção tecnológica faz surgir uma dupla contribuição: de um lado, o que é tecnológico não provém tanto de uma exterioridade do instrumento, mas de uma interioridade do sujeito social - não estávamos convencidos disso na época - e, de outro, é na indivisibilidade fundamental entre o "adquirido" e a "faculdade" no gesto e na palavra que a "realidade técnica" se inscreve, relegando assim sempre o instrumento ao segundo plano.

\begin{abstract}
A coleta das ferramentas e dos produtos da atividade material não basta para definir as técnicas, apenas garante que elas a salvaguardam dos materiais científicos que serão mais tarde interrogados como simples documentos de arqueologia, privados do tecido dos gestos e das intenções que faziam deles elementos da vida étnica. A tecnologia interessa tanto à pesquisa de um quadro teórico geral nas operações manuais como a do papel da técnica na montagem (assemblage) étnica; como os outros ramos, a tecnologia oferece-se ao mesmo tempo como o estudo das operações comuns a uma civilização ou a certa fase de evolução e como a análise dos elementos incorporados numa fórmula étnica (Leroi-Gourhan, 1968, p. 1820-1821).
\end{abstract}

Poderíamos dizer que ele faz assim das técnicas do corpo, tecnologias do sensível. Sua contribuição principal reside na abordagem da técnica como forma de expressão e mecanismo de socialização, privilegiando certo paradigma da relação: "[...] a unicidade étnica no tempo e no espaço, escreve ele, não é na realidade nem nos objetos nem nas instituições, mas nas relações" (Leroi-Gourhan, 1968, p. 1821). A partir desse programa, a armadura técnica vem revelar os constructos identitários - diria ele, "étnicos" - além de toda institucionalização (representações nacional-estaduais, socioeconômicas, territoriais e tecnocráticas). Trata-se antes de perguntar como uma estética torna-se um alvo coletivo. Centrar a questão nas suas aplicações e efeitos na vida social pode evitar exageros em construir descrições e interpretações ou, ainda, em pro- 
ceder ao estabelecimento de um simples catálogo de gêneros e práticas não refletindo a necessidade para os homens de cultivar uma relação sensível, esteticamente investida, no mundo, opondo-se aos supostos determinismos sociais aos quais seriam submetidos.

Para André Leroi-Gourhan (2004b, p. 88), de fato, "a técnica, a linguagem e a estética" não são somente "as três manifestações fundamentais da qualidade humana", mas, também, são "solidárias" e devemos observá-las em sua "relação".

Essa apreensão é aplicável a todo grupo que se faz coletivo agremiando-se em torno de um conjunto de técnicas do corpo, servindo a ele para exprimir um conjunto de valores identitários, mas também para criar seus próprios regimes de identificação (Rancière, 2000) internos, e não uma identidade calcada sobre um corpus de enunciados institucionalizados fora do grupo. Nesse grande conjunto de montagens de técnicas, achamos evidentemente estes objetos com os quais a Etnocenologia e os Performance Studies fizeram sua especificidade, e que nomeiam respectivamente formas performativas, espetaculares e performances. São todas formas de expressão mais ou menos espetaculares, mais ou menos construídas, mais ou menos codificadas, e nas quais o corpo é engajado de um certo jeito. Além disso, o aparelho epistemológico e metodológico desenrolado no seu programa, e pelo qual vamos nos interessar agora, é latente ou prorrogado na produção científica de outras disciplinas, diferentes das que são tradicionalmente associadas ao estudo das artes cênicas na França, como a Antropologia e a Filosofia. Isso permite evitar o uso das epistemologias problemáticas do campo teatral e do campo da performance, abordando as práticas espetaculares por um caminho analítico diferente.

Em 1968, André Leroi-Gourhan (1968, p. 1823) apresenta essa formulação, reunindo de modo inédito a soma do seu programa.

As nuances são, contudo, o elemento definitivamente significativo e a estética no sentido lato poderia sim ser uma das chaves da etnologia. Se fosse assim, teria verdadeiramente uma ciência a criar, aquela dos valores, 
dos ritmos, dos sabores e das formas, numa sistemática adaptada às necessidades do indefinível étnico [...].

Encontramos aí as preocupações do autor pela totalidade, a concepção maussiana das técnicas do corpo e a estética como projeto antropológico. Devemos igualmente identificar nessa formulação uma atualidade impressionante num momento no qual a técnica (a tecnologia e as novas práticas resultantes dela) parece se desenvolver mais rapidamente do que nossas análises sobre ela, um deslocamento difícil, mas urgente para pensar em relação à sua incidência nas formas e nos ritmos novos do mundo, e o que podemos dizer sobre eles na distância da análise. Ela contém os três eixos, formulando uma epistemologia da complementaridade e, assim, nos parecendo pertinente para o estudo das práticas performativas: 1) a atenção para as "nuances", 2) "a estética em sentido lato" como "uma das chaves da etnologia", 3) um certo paradigma de "ritmo" (seus valores, sabores e formas) para, enfim, a elaboração de uma "sistemática adaptada às necessidades do indefinível étnico" (Leroi-Gourhan, 1968, p. 1823).

\section{Nuances}

Em primeiro lugar, as nuances do objeto investigado inserem-se sempre num conjunto de objetos similares, mas cujas categorias vernáculas (gestos, palavras e representações) e os modos de apropriação, definem uma singularidade que as distingue nesse conjunto. Em segundo lugar, as que o pesquisador deve tomar em conta na restituição da análise: eis onde atua a experimentação etnográfica (Leroi-Gourhan, 1968). A partir daí, podemos desenvolver a exigência da nuance, segundo três perspectivas: a modalidade, a reflexividade, e a apreensão da diferença, nas quais um olhar micrológico (a obsessão do detalhe) e uma crítica constante da linguagem são transversalmente condicionais.

Porque as nuances fazem sentido e são significativas em toda prática corporal, e exacerbam-se na expressão das práticas nas quais as corporeidades são particularmente construídas, sua apreensão teórica deve comprometer-se com a 
modalidade em antropologia. A implicação da modalidade em Antropologia, que François Laplantine desdobra em sete proposições (2005, p. 185-216), permite repor a apreensão delas na temporalidade e nas suas ínfimas transformações. Para o autor, trata-se de uma

[...] démarche que permite apreender os modos de vida, de ação e de conhecimento, as maneiras de ser e, mais precisamente, ainda, as modulações dos comportamentos, inclusive os mais aparentemente anódinos, não somente na relação com o espaço, mas na dimensão do tempo, ou melhor, da duração (Laplantine, 2005, p. 185).

Forjado a partir de seu sentido musical (modos menor e maior) e gramatical (modos da conjugação verbal) (Laplantine, 2005), o qualificativo modal centra a atenção sobre a intensidade e a plasticidade própria ao fenômeno estudado no tempo e no espaço, mas, também, sobre a percepção que o pesquisador tem delas. Ele remete, assim, à "[...] reintegração da experiência sensível do tempo em nosso modo de conhecimento" (2005, p. 190), privilegiando o processo sobre o produto, o fazer sobre o fato. Isso implica tomar em conta as diversas realidades que percebemos da experiência do fenômeno que estudamos. A atenção à modalidade não pode prescindir de uma abordagem crítica da linguagem, quer dizer, resistir ao seu uso autoritário e utilitário, o qual confunde a informação ou a comunicação com a produção de conhecimento. Trata-se, ao contrário, de usar a linguagem para dizer "o que a excede", ou seja, o percepto, reorientando-se para o "[...] pensamento de uma solidariedade do conceito-afeto que é uma solidariedade conflitual, quer dizer, para uma implicação recíproca da vida sensível do sujeito, da história e da linguagem no seu relacionamento ao que não é propriamente dito linguageiro" (Laplantine, 2005, p. 211).

Pensar o sensível remete assim a uma exigência de rigor, não podendo elidir a linguagem, a qual é articulação e mediação. E, para o autor, a estética é uma dessas "mediações" (2005, p. 213). É "esse desvio [escreve Laplantine], em relação à linguagem, num trabalho de reorganização perceptiva e auditiva, que deve ser reivindicado" (2005, p. 217). As práticas 
performativas, distinguindo-se pelo seu grau de construção, de codificação e de intenção, são suscetíveis de se beneficiarem da exigência modal ao observar os desvios entre as categorias do discurso (verbal e gestual) e sua realização, resistindo à tentação semiológica e reduzindo uma prática à um objeto flutuante independente de todo contexto social, colocando a validade do percepto contra a teorização e a conceptualização ultrajantes. Daí a importância de manter uma postura micrológica à atuação dos corpos, dos sons, das imagens e da linguagem para alforriar-se da semiologia contra a decomposição e a supressão do vínculo social, e restituir a polifonia da realidade através de um olhar globalizante.

Evidentemente, não existe perspectiva modal possível sem uma reflexividade crônica, traduzida por essa crítica constante da linguagem. Como mostraram, entre outros, Pierre Bourdieu (1980) e Henri Meschonnic (2009), nossa percepção e o corpus linguístico à nossa disposição para descrevê-la e analisá-la, são histórica e socialmente construídos. Os Performance Studies (Schechner, 2002) e, em seguida, a Etnocenologia (Bião, 2009; Pradier, 2007) apreenderam, para o estabelecimento dos seus métodos respectivos, a reflexividade tal como suscitada pela sua erupção no debate e na constituição de uma antropologia da performance turneriana, ela mesmo derivada do encontro entre artistas do teatro e antropólogos. A exigência de reflexividade, derivada inicialmente do questionamento da metodologia de campo e proposta pela Escola de Chicago, é diretamente herdeira das tendências fenomenológicas que Alfred Schütz tinha desenvolvido na sociologia (Le Breton, 2004b). A estética estava aí já concebida em termo fenomenológico, mas, também, no paradigma da relação social, sem ser confundida com o domínio das artes. Devemos notadamente à Clifford Geertz uns dos apontamentos mais incisivos sobre o problema da percepção, da recepção e da reconstituição pelo etnógrafo. No epílogo da obra póstuma de Victor Turner The Anthropology of Experience no qual são discutidas as problemáticas do "text as performance" ou "performance as text", ou seja "da vida dos signos na sociedade" (1986, p. 380), Geertz mostra como "a vida dos símbolos" destrói as binaridades, destacando 
os contrastes emitidos por todo sujeito entre sua experiência do evento e seu "interpretative replay" (Geertz, 1986, p. 380), sublinhando a capacidade da experiência, mesmo reatuada, para originar (originate), ao infinito. "É tudo uma questão de arranhar superfícies" (Geertz, 1986, p. 373), escreve ele, e é com certeza através de nossas experiências que alteramos a realidade. Nós não nos estenderemos sobre a necessidade da mobilização da reflexividade. Porém, a atenção para as gradações nas nuances da expressão e da percepção, induzindo uma postura reflexiva firme, trazem à luz a importância da apreensão da diferença em toda produção humana e, mais ainda, quando ela é projetada no espaço comum do social.

A atenção para as nuances implica um pensamento da diferença como singularidade/irredutibilidade e como intraduzibilidades culturais. Leroi-Gourhan as ligava, com essa sua terminologia um pouco datada, aos processos de "spéciation" e de "diferenciação das etnias", os quais ele tomava ao mesmo tempo como fundamento e como prova da etnologia: "a busca das leis de particularização" (Leroi-Gourhan, 1968, p. 1119). As nuances como enunciações sonoras, visuais, olfativas participam da produção da diferença através desse "indefinível étnico", e claro, nos confrontam com os nossos limites quando queremos traduzir ethos formados por um grupo nas suas práticas corporais. Para Leroi-Gourhan, as técnicas agenciando esses ethos devem ser consideradas como "montage[ns] origin[ais] e completa[s]" (1968, p. 1819 e seguintes) para contrariar o risco de produzir uma justaposição de informações e reduzir a etnografia à sua função de registro ${ }^{8}$. Desse modo, a diferença como singularidade (irredutibilidade cultural) e intraduzibilidade (os limites da linguagem) devem ser rigorosamente apreendidas juntas.

A antropologia do corpo e das emoções, a partir da experiência sensível na qual as percepções sensoriais e a expressão das emoções são social e culturalmente modeladas, evidentemente são partes do projeto. Tais como foram inauguradas na França por David Le Breton (obras originalmente publicadas em 1990 e 1998), seu interesse é que "são relações" que implicam "simultaneamente a diferença ao mesmo tempo 
coletiva e individual, quer dizer a sucessão das culturas e no seu seio as maneiras singulares pelas quais os indivíduos se apropriam delas" (Le Breton, 2004a, p. 9). O autor ainda expõe ao seu modo a tríade de Mauss, podendo servir de base a uma antropologia da estética centrada nas "culturas afetivas" (Le Breton, 2004a, p. 179-190) nas quais um "[...] termo emocional se entende somente dentro de um ethos próprio" (2004a, p. 180). E esse ethos próprio constitui-se, nas práticas corporais artísticas ou não, espetaculares ou não, a partir de técnicas através das quais os grupos instrumentalizam suas relações com o mundo. É por essa instrumentalização, como construção, que os grupos fabricam a irredutibilidade de sua singularidade cultural coletiva. Assim sendo, as nuances como diferenças são centrais no sentido em que desvelam o jogo da partição, ao mesmo tempo coletivo e individual, das partilhas do sensivel (Rancière, 2000).

O estudo das práticas corporais, notadamente as espetaculares, não pode elidir suas dimensões políticas. Estas últimas não se revelam em particular sobre a cena, e menos ainda sistematicamente no discurso (gestual ou verbal) encenado, mas na maneira de dar luz, distribuir e receber esse discurso. Os Estudos Culturais e, especificamente, os Estudos Póscoloniais, acenaram com a noção de diferença, amplamente impregnada das teorias ditas pós-modernas como a de Derrida e sua noção de signature (1967), reintroduzindo-a como valor e fonte suscetível de reconstituir ou descrever menos ideologicamente a realidade plural dos processos de socialização. Para Homi Bahbha, "[...] a enunciação da diferença cultural problematiza a divisão binária entre passado e presente, tradição e modernidade, ao nível da representação cultural e do seu discurso autoritário" (2007, p. 78). Do mesmo modo, não podemos subestimar que "[...] a emancipação começa [...] quando entendemos que as relações (rapports) do dizer, do ver e do fazer pertencem à estrutura da dominação e da sujeição" (Rancière, 2008, p. 19). Essas relações do dizer, do ver e do fazer são performatividades que revelam mais sobre as relações sociais porque se elaboram a partir de uma troca direta entre indivíduos e tornam contingentes seu devir. No 
mesmo sentido, Judith Butler, outra teórica das "políticas do performativo" ou da puissance d'agir como política, labuta contra toda naturalização proveniente da redução da realidade à linguagem, pois "[...] o performativo social desempenha um papel crucial não somente na formação do sujeito, mas igualmente na contestação política e na reformulação contínua do sujeito" (Butler, 2004, p. 210). Essa diferença proveniente da "reformulação contínua do sujeito" tem mais força ainda quando enunciada (gestual e verbalmente) de maneira repetida, reiterada. Para ela, a puissance d'agir contida no performativo ou na performatividade (performativity) reside no fato de que toda ação ecoa em "[...] ações anteriores e acumula a força da autoridade através da repetição ou da citação de um conjunto de práticas anteriores que produzem autoridade": não há, então, nenhuma "[...] força performativa sem essa historicidade acumulada e dissimulada" (Butler, 2004, p. 100) pelo próprio sujeito. Evidentemente, essa análise da ação verbal vale para os gestos e isso independentemente do seu grau de construção. Se "[...] a essência da política reside nos modos de subjetivação não consensuais que manifestam a diferença da sociedade para ela mesma" (Rancière, 2004, p. 251-252), então, as práticas espetaculares fornecem esses mecanismos para ler através do exercício verbal, sonoro e gestual dos praticantes em ato, pois encontram-se aí mais ou menos liberados de uma camisa de força jurídica ou institucional estabelecida no consenso social.

As relações entre a experiência e a expressão do sensível dão a ver e entender o jogo das distribuições sociais para além do jogo da institucionalização. O que devemos perceber, como diz o filósofo Jacques Rancière, é que "[...] as oposições definem propriamente uma partilha do sensível, uma distribuição a priori das posições e das capacidades e incapacidades amarradas a essas posições. São alegorias encarnadas da desigualdade" (Rancière, 2008, p. 19). A consciência dessa desigualdade, e tomando ela em conta, são indispensáveis para se desfazer de todo etnocentrismo: certos modos de fazer não ficam aproximáveis pelos instrumentos linguísticos da instituição na qual se inserem. Esses enunciados institucionais trazem à luz a inconciliabilidade das duas lógicas da arte, sua 
geração e seus dispositivos, acreditando poder confundir as práticas significantes para o grupo que as exercem, com suas representações. Podemos tentar, ao contrário, como propõe Homi Bhabha, desfazer-se de uma análise "[...] na qual o texto Outro é para sempre o horizonte exegético da diferença, nunca o agente ativo da articulação" (Bhabha, 2007, p. 73) e ser atento, ainda que seja difícil, ao momento no qual

[...] o Outro perde seu poder de significar, negar, instaurar seu desejo histórico, estabelecer seu próprio discurso institucional e oposicional. Ainda que bem conhecido que seja o conteúdo de outra cultura, se anti-etnocêntrico que possa ser sua apresentação, é a sua localização como o ponto de fechamento das grandes teorias, a demanda, em termo analítico, que ela seja sempre o bom objeto do saber, o corpo dócil da diferença, que reproduz uma relação de dominação e constitui a acusação mais grave contra os poderes institucionais da teoria crítica (Bhabha, 2007, p. 73).

Essa atenção é mais necessária quando estudamos cada vez mais práticas provindas da aceleração global do fenômeno diaspórico, e práticas derivadas de diversos gêneros espetaculares já estabelecidos, ou de estatutos diversos ou ainda inéditos. Uma análise da categoria, em língua portuguesa, da ação brincar $^{9}$ foi pertinente a esse respeito. É frequentemente a modalidade da ação - suas qualidades - que politiza, quer dizer que injeta esse desvio ou esse dissenso, a diferença de uma sociedade por ela mesma. Nesse sentido, a introdução, na apreensão das práticas performativas, da política como manifestação de um dissenso no espaço social, a política somente na medida em que manifesta essas partilhas do sensível historicamente instituídos e acumulados, parece essencial. De fato, se definirmos uma comunidade estética pelo fato de ela se reunir em torno de técnicas e maneiras de produzir, fabricando um conjunto simbólico atrás do qual seus membros entendem manifestar certa identificação, sabemos que alguns de seus membros agem dentro do grupo ao qual pertencem, não reconhecendo esse aparelho em sua sensibilidade, ou pior, podendo remeter ao que é concebido nele por beleza. Nesse sentido, podemos citar a abordagem do corpo pelo antropólogo 
Pierre-Joseph Laurent (2010) que analisa a beleza em termo "de desigualdade fundamental" (p. 35). É a velha história da problemática da arte em antropologia: os modos de apropriação da produção estética não se dissolvem na diversidade cultural. Para o autor, o corpo é, ao mesmo tempo, um dado e um constructo, pois

[...] o corpo objeto é o próprio corpo, de uma 'estética já aí'. Ele remete a uma repartição desigual da beleza e a uma 'singularidade dada'. $\mathrm{O}$ fato de basear-se sobre critérios universais ou de proceder de convenções culturais, evolutivas e negociáveis, não muda fundamentalmente a questão. Esse corpo próprio é, então, aquele que cada humano deve apropriar-se. É questão, assim, de um corpo construído que se torna um corpo sujeito capaz de exprimir uma identidade cultural particular em favor do reconhecimento que o entorno lhe confere (Laurent, 2010, p. 40).

\section{"A estética no sentido lato como uma das chaves da etno- logia"}

Não precisamos insistir sobre o fato que a noção de estética é problemática em si mesma, europeocentrada, polissêmica e polêmica, e cuja utilização traz a confusão segundo as terminologias acadêmicas. Assim, para tentar atingir esse sentido lato do qual fala Leroi-Gourhan, e que ele seja operatório sem forjar reducionismos, podemos paradoxalmente restringi-lo à sua etimologia grega, aisthesis, tal como definida acima. Isso é entendido aqui como um processo, uma relação sensível com o mundo, estabelecido pelo fenômeno da experiência que não tem mais nada a ver com a "teoria da arte", a qual, como Hans R. Jauss o notava em 1972, "[...] ficava limitada à ontologia do objeto estético e, mais frequentemente, abandonava os problemas resultantes da práxis estética à poética normativa ou à teoria subordinada dos afetos" (Jauss, 1978, p. 144-145). Práxis e afeto são, ao contrário, a combinatória essencial do nosso programa. Ao recorrer a uma apreensão mais apologética ${ }^{10}$ da experiência estética, Jauss desenrola, com outros, um verdadeiro projeto antropológico.

De fato, para reintroduzir a estética como práxis e defender a função social da arte e das disciplinas científicas às 
suas ordens, Jauss formula quatro teses. Em primeiro lugar, a experiência subjetiva desemboca sobre a experiência intersubjetiva (1978) porque o gozo necessário à experiência subjetiva distingue-se do gozo sensual pela "[...] distanciação do sujeito e do objeto" (Jauss, 1978, p. 142): a experiência estética tornase, então, não somente uma relação entre o sujeito e o objeto e não é mais reduzida às propriedades supostamente específicas do objeto, mas origina inevitavelmente esse distanciamento reflexivo levando-nos à conceptualização, fundamental tanto para o etnólogo, quanto para o artista. Em segundo lugar, a experiência estética é emancipatória, operando não somente a “[...] libertação de alguma coisa (catharsis), mas para alguma coisa" (Jauss, 1978, p. 143): lembrando Paul Valéry notadamente, Jauss mostra que a prática da arte torna-se o exercício de um poder poïético, e esse duplo aspecto da produção/recepção garante uma função cognitiva, a produção de conhecimento. Esse conhecer não é mais, na percepção estética, um reconhecer, mas uma descoberta, quer dizer não se trata de um "[...] simples retorno contemplativo para qualquer verdade preexistente, mas um 'conhecer' dependendo de um poder experimentando-se no agir [...]", de tal modo que "[...] compreender e construir já são uma única e mesma operação" (Jauss, 1978, p. 152). Em terceiro lugar, "[...] a percepção estética é uma instância de crítica da linguagem e da criação" (Jauss, 1978, p. 160) e esse valor operatório e cognitivo da percepção estética tira a oposição entre gozo e ação, atitude estética e prática moral ou ética. Jauss reconhece, então, a experiência estética como certa "razão prática" (Jauss, 1978, p. 169), bem antes da contribuição neurológica de Erro de Descartes ${ }^{11}$. Em quarto lugar, a experiência estética só terá uma função social na medida em que não será reduzida à experiência da obra ou à experiência de si mesmo, mas se ela abrir-se para uma experiência do Outro (Jauss, 1978, p. 161). Extremamente simplificada aqui, essas teses participam da reabilitação da percepção estética no processo social e da reconsideração de suas funções socializantes e individuantes. Nas práticas corporais codificadas, na perspectiva da realização de um produto artístico ou não, cênico ou não, o fato do corpo ser o médium através do qual 
a experiência é realizada, sendo simultaneamente a fonte e o alvo da percepção, dão a ler os processos de individuação e de socialização, mas também a entender o papel do fenômeno coletivo do investimento estético na construção de um grupo a partir de suas diferenciações em relação a um Outro, abrangendo o primeiro. Expondo as alterações que operamos sobre a realidade graças à experiência estética, essas teses afirmam a consistência antropológica da estética.

A exacerbação da ontologia do objeto nas ciências da arte que Jauss evoca foi desconstruída de maneira interessante pelo filósofo Jean-Marie Schaeffer, mobilizando, ele também, explicitamente a antropologia. O estudo das práticas performativas apresenta o risco de acabar por estabelecer repertórios descritivos de técnicas sem colocar o objeto no seu contexto e na sua rede de relações. Schaeffer lembra que as projeções segundo as quais um objeto estético teria propriedades perceptivas internas supernumerárias (propriedades físicas e arte-factuais, artefactuelles) ou relacionais (propriedades intencionais e funcionais) são culturalmente construídas e eurocêntricas. Para ele, "[...] contrariamente às aparências, o que apresenta problema na expressão 'objeto estético', não é o segundo termo, mas o primeiro: pensar a dimensão estética em termos de objetos proíbe nosso acesso à realidade dos fatos estéticos" (Schaeffer, 2004, p. 29). Para apreender a especificidade desses objetos nesse sentido, ele propõe as noções de sobrecusto da atenção e de relação estética.

Schaeffer (2004) constrói a noção de sobrecusto a partir de duas outras: "sistema de informação custoso" que Roland Barthes tinha formulado para descrever e definir "a arte numa mensagem verbal", "[...] modo de evitar toda restrição da poética à poesia e bem marcar que se trata de um plano geral da linguagem comum a todos os gêneros" (Barthes, 2002b, p. 1272); e "arquitetura da função puramente ostentatória", elaborada por Carl T. Bergstrom (2001) a partir de uma teoria biológica dos signos dos animais. Por "signos a custo elevado", ele entende "[...] toda produção de signos contrapondo-se ao princípio da economia, regulando em geral as atividades vitais" (Schaeffer, 2004, p. 43). Uma distinção é importante aqui: não podemos 
confundir a atenção com a intenção estética, pois a intenção estética não gera automaticamente um sobrecusto da atenção estética. Esta última apresenta pelo menos duas vantagens: descrever o trabalho da estética como relação sensível entre um indivíduo (psíquico ou coletivo) e o objeto da sua atenção, sem passar pelo único prisma de uma representação mental prévia, do objeto ou de um único determinismo social, controlando seu corpo; descrever a particularidade dessa relação gerada de uma construção específica do objeto, sem atribuir a ele propriedades sensíveis supostamente supranumerárias (como em objetos de arte, belas-artes). Além disso, ela não apresenta nenhum marcador etnocêntrico, social, econômico ou estatutário. A esse respeito, Schaeffer (2004, p. 42) vê nela uma "constante transcultural e trans-histórica".

Depois da proposta de Gérard Genette (1997), Schaeffer propõe outra ferramenta pertinente, a conduta estética para iluminar aquela de relação. A polissemia do termo conduta (bastante análogo àquele de prática, contudo sem evocar a repetição) mostra de fato as dissensões sutis entre o que a governa $^{12}$, e suas interações num contexto dado. Assim, ela coloca a questão da intenção. Para Genette, o termo designa a démarche de um sujeito colocando-se num estado propício para fazer essas experiências ou para provocá-las, gerando desse modo uma relação estética: a atuação da estética (fala ele de l'ouvre de l'art) é, assim, relação. Aliás, a individuação que essa propicia é suscetível de levar à participação no sentido em que Gilbert Simondon escreve, pois “[...] a participação, para o indivíduo, é o fato de ser elemento numa individuação mais larga pelo intermediário da carga de realidade [...] dos potenciais que ele contém" (Simondon, 1989, p. 18). No projeto de uma antropologia da estética aqui concebida, a relação estética é reconhecida como motor e como motivo do social.

Schaeffer $(2004$, p. 14) retoma a noção de "conduta estética", reorientando sua apreensão, mas de maneira moderada, para as ciências cognitivas. Trata-se de "uma atividade e não de uma atitude passiva", "de discriminação cognitiva de discernimento" (p. 17) que "pode comportar componentes imaginativos" (p. 16) e, enfim, "[...] acompanhada de uma satisfação 
experimentada na própria atividade cognitiva" (p. 17). Para fazer dessa ferramenta uma ferramenta "transcultural e transhistórica", devemos admitir sua competência relacional, “[...] distinguindo entre a ativação estética de um objeto ou de uma representação e as funções eventuais nas quais essa ativação encerra-se" (2004, p. 43). Essa distinção é essencial na medida em que, desse modo, as práticas espetaculares não podem mais ser confundidas com os dispositivos da arte que são de uma parte institucionalizados, quer dizer socioculturalmente construídos e reconhecidos e, de outra, constrangimentos entre outros espaciais, temporais, tecnológicos, sonoros etc. adjacentes, mas que podem ter um impacto inalterável sobre a formatação delas. Isso leva a ver o que Jacques Rancière (2000, p. 90) chama de 'regimes de identificação da arte': um regime "[...] no qual a arte é identificada por um modo de ser sensível próprio a seus produtos". No entanto, não há arte sem que um grupo recorra a sua identificação interna. Não basta haver pintores ou músicos, atores ou dançarinos para que uma forma de arte seja identificada. $\mathrm{O}$ autor afirma que, para haver arte, "[...] ainda é necessário que suas performances sejam o objeto de olhares, discernindo nelas uma esfera de atividade específica, de discernimento, argumentando essa especificidade, e instituições dando corpo a essa visibilidade" (Rancière, 2004, p. 15). Esses regimes de identificação da arte não devem ser confundidos com os dispositivos das artes, mesmo se eles coexistem.

\section{"Uma ciência [...] dos valores, dos ritmos, dos sabores e das formas"}

Toda sociedade produz culturas afetivas por intermédio de práticas tecnicamente codificadas e esteticamente investidas. A atenção micrológica do olhar sobre as modalidades da codificação e do investimento estético é necessária para não reduzir a complexidade e a singularidade de cada uma. $\mathrm{O}$ conjunto das noções de valores, ritmos e formas tomam mais consistência ainda nas práticas nas quais as corporeidades são especificamente objetos de construções formais e imaginárias, nas quais técnicas constroem conhecimento. Mas a episte- 
mologia do ritmo teria aqui um valor paradigmático, assim como aquela da relação. Todo sujeito implicado numa prática espetacular fabrica uma ética coletiva a partir de instrumentos técnicos (inclusive o corpo) cuja singularidade provém da produção de um ritmo pela instrumentalização de valores (imaginários), sabores e formas (concretas).

A partir do que Bruno Karsenti (1998) tomou da proposta de Leroi-Gourhan, é a maneira pela qual o homem projeta-se para fora que faz de um fenômeno técnico ou de uma tecnologia um fato social total, carregando sua historicidade. Karsenti (1998, p. 234) identifica a noção de "biologia da técnica" como "o lugar epistemológico" do programa de Leroi-Gourhan (2004a), investido de uma dupla intenção: resituar o fenômeno técnico numa dinâmica vital, determinando o sentido e as modalidades dela; e tomar em conta as formas sociais de existência nas quais essa dinâmica realiza-se necessariamente (Karsenti, 1998). Evidentemente "[...] o corpo como corpo técnico, quer dizer, como corpo expulso dele mesmo pelas suas forças próprias, e exposto sobre o espaço comum do social" (Karsenti, 1998, p. 236-237) é o obstáculo fértil com o qual Leroi-Gourhan articula seu pensamento. Ao tratar da memória do corpo como de uma memória específica, com seus próprios "mecanismos de conservação, estabilização e de integração", ele poderia resolver a contradição proveniente da expressão "técnica do corpo": pensar simultaneamente o que diz respeito a uma faculdade própria (a criatividade) e ao adquirido (habitus).

O que o fenômeno técnico, em sua diversidade mesma, torna materialmente visível é, no fundo, nada mais do que a dinâmica propriamente humana do desenvolvimento (déploiement) de certo comportamento técnico, de sua inscrição no mundo sobre diferentes formas instrumentais. O que é humano, e somente humano, é antes de tudo a projeção para fora, sobre uma cena obrigatoriamente coletiva, dos órgãos da tecnicidade - de uma tecnicidade que não para de ser orgânica enquanto afirma-se no modo instrumental (Leroi-Gourhan apud Karsenti, 1998, p. 238). 
A maneira pela qual Leroi-Gourhan aborda a técnica, como uma "[...] opção biológica inscrita no elemento corporal, conduz inevitavelmente a uma concepção fundamentalmente vitalista da matéria, que a apresenta sob a luz desconcertante de um tipo de organologia geral" (Karsenti, 1998, p. 238). Essa concepção não permite, então, encerrar a concepção social da técnica numa "potência própria do social sobre o corpo" - o que acontece com as leituras demasiadamente radicais do biopoder de Foucault - mas sim, mostrar a solidariedade das "montagens físio-psico-sociológicos" (Karsenti, 1998, p. 240).

À escala dos corpos, a inseparabilidade da mobilidade do instrumento (necessário à técnica) e da contextualização social do gesto (o ciclo operatório) constitui, para Leroi-Gourhan, esse vitalismo. Essa obsessão de pensar a matéria e a vida em ato já foi creditada de uma espécie de misticismo obscuro na história da antropologia francesa ${ }^{13}$. Ora, assim concebido, o vitalismo só pode ser reabilitado numa antropologia da estética alargada. Assim essa espécie de organologia geral não tem nada de desconcertante, mas participa de uma visão energética do mundo, tal qual concebida, entre outros, por Édouard Glissant. O poeta filósofo observa o processo social em ato que transborda largamente hoje a descrição das mutações das sociedades ditas crioulas ou ditas fundamentalmente híbridas - através da noção de crioulização que é, senão, um processo rítmico e sensível. Esse processo em ato, que ele desenvolve em seu conceito de "Relação" designa a "força poética como energia do mundo" (Glissant, 1990, p. 173), quer dizer a estética (o sensível) como agir poïetico. Essa concepção implica certo paradigma da ritmicidade, cada vez mais essencial a considerar e que deveria ressoar em várias dimensões da abordagem das formas espetaculares em particular. Esse paradigma, já presente em Mauss (2002, p. 126) como irredutibilidade da humanidade ("social e individualmente, o homem é um animal rítmico"), associado ao sensível (a partir de Boas, "onde tem ritmo, tem geralmente estética") (Mauss, 2002, p. 127), é seguido por Leroi-Gourhan: o ritmo é o que permite descrever e o que opera a "montagem original e completa" numa "coletividade tida como única" (Leroi-Gourhan, 1968, p. 1919). 
A noção de ritmo desenvolve, ela também, um pensamento sobre a socialização e sobre o político, como bem evidenciou Pascal Michon (2007, p. 37) a partir de um aparelho conceitual cruzando, de um ponto de vista "radicalmente histórico" as "[...] dinâmicas dos grupos sociais, dos corpos e da linguagem humanos" (Michon, 2007, p. 40). Segundo ele, contrariamente à noção de estilo que, ainda que identifique os indivíduos por diferença, visa, contudo, a liberá-los de toda distinção; e diferentemente da noção de ritournelle (Deleuze; Guattari, 1980) que indica uma organização autônoma da individuação, a noção de ritmo designando "a organização do movente", é dotada de "uma dimensão formal, mas irregular, sem regra nem dimensão transcendental" (Michon, 2007, p. 41). Essa concepção do ritmo, largamente tomada de empréstimo do sentido desenvolvido por Henri Meschonnic em sua Antropologia Histórica da Linguagem (2009), acentua seu caráter individuante: corporal ou linguageiro, o ritmo é a organização do sujeito como discurso, em e através de seu discurso. Porém, consciente do caráter restrito à arte dessa definição, porque um processo rítmico não desemboca necessariamente sobre uma individuação plena e inteira, Michon admite que essa proposição, "demasiadamente teórica", não convém exatamente ao estudo das corporeidades no processo social (Michon, 2007, p. 43-46). Trata-se melhor de considerar o processo social como uma "[...] montagem de técnicas [...] que determinam as maneiras de fluir, quer dizer as variações das interações de um conjunto de seres humanos [...] constitu[indo] 'idiossincrasias históricas"' (2007, p. 71). No seu curso no Collège de France Como viver juntos?, Roland Barthes (2002a) introduziu um pensamento antropológico da semiologia, desenvolvendo notadamente as noções de ritmo e idiorritmia (idiorrythmie). Michon as reelabora nesse ritmo entendido como "maneira singular de fluir" (a partir do grego rhutmos stricto sensu, que não é sinônimo de metros, mas contém o metros somente na medida em que é uma de suas várias modalidades), podendo descrever a discursividade, a socialidade e a corporeidade em ato, ou seja a "[...] produção dos indivíduos [...] indissociavelmente singular e coletiva na sucessividade do tempo" (Michon, 2007, p. 72). 
Enfim, Leroi-Gourhan associa as noções de "sabores" e "formas" ao que entendia, com a terminologia de sua época, por "o indefinível étnico", quer dizer a singularidade da criatividade em ato irredutível e frequentemente intraduzível, de um grupo sociocultural. No seu artigo L'expérience ethnologique (1968), ele define a especificidade da etnologia, iluminando a singularidade em ato por intermédio da utilização de técnicas por grupos sociais, podendo distingui-las na diversidade. A tarefa do etnólogo é "particularizante" e visa ao "singular" contrariamente a do antropólogo, "generalizadora" e visando melhor as leis de "estrutura" (Leroi-Gourhan, 1968, p. 1817). Para ele, a "experiência etnológica" é "[...] uma etnografia através da qual exercita-se a vigência de uma percepção da organização original dos traços de um grupo étnico", e cessa de ser etnológica quando "[...] renunciamos a considerar a etnia como uma montagem original e completa" (Leroi-Gourhan, 1968, p. 1819).

Essa démarche é precisamente a do artista ou a do grupo que constrói técnicas através das quais funda sua identificação. Ela é, também, útil para o estudo das formas espetaculares e artísticas. No seu curso Le Neutre, Barthes recorre a uma definição performativa da noção latina de qualitas, uma puissance d'agir irredutível que ele apresenta "como energia" (2002a, p. 86): “[...] a qualitas, é o que desce sobre 'as coisas' (em sua indistinção) e imprime-se como força de distinção, de especificação, de nominação" (Barthes, 2002a, p. 86). Trata-se ao mesmo tempo de uma "[...] força agindo, algo que arremessa-se, jorra e eleva-se, que 'qualifica', quer dizer algo que faz de uma coisa uma tal coisa" (2002a, p. 86), sem falar de um ponto de vista unicamente linguístico ${ }^{14}$. Depois de ter apontado que uma qualidade pode ser definida somente em relação a outras, o autor termina dizendo que produz o pensamento de um certo Neutro ("um terceiro termo complexo e não termo zero" (2002a, p. 87), que ele entende além disso como um "valor ativo" (Barthes, 2002a, p. 262). De fato, para ser rápida, todas as qualidades se valem a priori, como levanta Leroi-Gourhan, através da técnica. É bem nesse ponto que, partindo de uma experiência etnológica, da singularidade sensível, podemos estabelecer uma certa antropologia. 


\section{Para "uma sistemática adaptada às necessidades da ex- pressão do indefinível étnico"?}

A reintrodução, nos estudos das práticas corporais, da técnica como porta para a historicidade de um grupo sociocultural na sucessividade do tempo e dando a ler, ao mesmo tempo, a singularidade e a variabilidade plástica de suas produções, pode contribuir para uma antropologia da estética alargada. A especificidade delas, sendo a exacerbação ou a inibição do jogo do bom e do belo na fabricação, manifestação, recepção e nos modos de apropriação, constitui a instrumentalização de suas produções, ela permitiria reintroduzir o sensível, ou seja, a estética como aisthesis, como grau zero de toda escritura corporal humana, ao mesmo tempo dada e construída.

A epistemologia desenvolvida aqui procura reunir as perspectivas antropológica e estética como elas se interpenetram na realidade, embora nossas tendências a desconhecer as singularidades do outro e a nos comprazermos com nossas projeções mentais fora do domínio sensível. Essas tendências, muitas vezes induzidas por terminologias incompreensíveis de uma sociedade para outra, pois são afastadas não tanto no tempo e no espaço, mas na linguagem, podem reduzir-se, contudo, cultivando a interpenetração e a complementaridade epistemológica, reveladas numa concepção paradigmática da relação e do ritmo, átomos irredutíveis de toda forma de estética.

A atenção dada às nuances - incluindo a apreensão dos constructos da modalidade, da reflexividade e da diferença - a partir da sustentação de um olhar micrológico e de uma crítica constante à linguagem, sobre as produções humanas, buscando projetar-se no espaço comum do social, pode evitar que se reforme a distância entre o percepto, o afeto e o conceito nas nossas tentativas de tradução dos ethos dos outros. De fato, onde há prática artística, não há só leveza criadora e prazer, há, também, constrangimento e relações de desprazer, devendo nos engajar a levar em conta as representações nas quais essas relações são encerradas e os dispositivos da arte nos quais são exercitas. Ademais, trabalhar com o grau de construção e de intencionalidade nesses modos de produção 
não é somente condição sine qua non para descrever esses mecanismos mas, sobretudo, revelar nelas com acuidade as questões de poder.

Manter o que devemos chamar de rigor dessa apreensão parece necessário tanto para a prática das formas espetaculares e para a prática etnográfica, quanto para suas teorizações respectivas: fazem parte da mesma démarche. Reinstaurar o sensível na técnica, é fundamentalmente dissociar arte e estética, para falar em termo de tekhnè e o que é nela esteticamente investido. Essa perspectiva poderia não somente evitar uma desumanização das técnicas, mas, também, evitar de proceder a uma industrialização do olhar sobre as práticas humanas. Vários episódios na história mostraram que sabíamos fazê-lo. 


\section{Notas}

${ }^{1}$ Este texto retoma a parte metodológica e teórica desenvolvida na minha tese de doutorado, Les Rythmes d'une Culture Populaire: les politiques du sensible dans le maracatu-de-baquesolto, Pernambuco, Brésil (Université Paris 8, dez. 2010). Claro, foi o objeto estudado que induziu essa abordagem epistemológica das práticas performativas.

${ }^{2}$ Ver a abordagem histórica da noção de estética por Hans Robert Jauss (1978, p. 135-172).

${ }^{3}$ Enquanto Armindo Bião rejeita a noção de performance e todos seus derivados (Bião, 2007 p. 48-49; Bião, 2011, p. 351) em função da confusão fundamental que causa a passagem para outra língua que não o inglês, Jean-Marie Pradier retém a de performativité (2007, p. C14-C15), contudo sem usar a de performance.

${ }^{4}$ Os tradutores de Judith Butler (2004, p. 14-16) Jérôme Vidal et Charlotte Nordmann, traduzem agency por "puissance d'agir", designando "ao mesmo tempo o que é ativo ou o que exerce um poder, e o 'princípio', a força motriz em ato (à l'œeuvre) numa ação dada” (p. 15). É precisamente a descrição do uso do termo por Judith Butler, o que produz o performativo ou a performatividade (performativity). Concordamos com essa escolha.

${ }^{5}$ Para esse assunto, ver Pradier (2007, p. C14). Para uma crítica do "operador performativo", ver Stiegler, (2005, p. 32-63).

${ }^{6}$ Essa dimensão é mais desenvolvida pelos Performance Studies, pois constituíram-se em particular a partir das Cultural, Subaltern e Postcolonial Studies (por ex. Schechner, 2000, p. 110-142) e a contribuição das críticas pós-modernistas e pós-estruturalistas.

${ }^{7}$ Apresenta um verdadeiro problema, a saber, a carência de aprofundamento devido à pluralidade de domínios de especialidades a dominar pelo pesquisador, mas também, um trabalho de longa temporada inscrevendo-se um pouco em contradição com as leis da produtividade científica de hoje.

${ }^{8}$ Nesse assunto, Leroi-Gourhan produziu uma reflexão sobre a imagem e o filme etnográfico em particular, que foi fundadora para a antropologia visual na França.

${ }^{9}$ Uma análise do substantivo brincadeira e do verbo brincar tais quais são concebidos pelos maracatuzeiros na Zona da Mata Norte de Pernambuco através do maracatu-de-baque-solto, mostra uma complexidade em ato como discurso e como modalidade de ação. Porém, esses termos não produzem essa complexidade na linguagem usual no Brasil. Essa reflexão toma mais sentido ainda considerando que o maracatu-de-baque-solto, como forma espetacular dita popular e realizada por subalternos na escala social, uma forma dita folclórica realizada por trabalhadores rurais da cana de açúcar, conheceu um longo período de discriminação social, étnica e estética na história do carnaval de Recife. Ver Garrabé, 2010, capítulo 5.

${ }^{10}$ Jauss apresenta essas teses num texto derivado de uma conferência de 1972, intitulada Pequena apologia da experiência estética e publicada na França em Para uma estética da recepção (2004) em 1978.

${ }^{11}$ Em O erro de Descartes, Antonio R. Damasio (L'erreur de Descartes, 2000) esforça-se 
em demonstrar este mecanismo, que nomeia "a razão das emoções", a partir da organização cerebral.

${ }^{12}$ Referimo-nos ao "governo dos corpos", tal como desenvolvido por Fassin e Memmi (2004, p. 12-29).

${ }^{13}$ Ver Morin, 1975. Roger Bastide, aluno de Mauss e colega de Leroi-Gourhan, foi acusado de vitalismo, notadamente depois de sua temporada no Brasil, porque deixava precisamente esse espaço aberto ao impensável explicitamente situado na experiência da tensão entre corpo e psiquè (uma tensão fértil na qual a religiosidade foi veículo). François Laplantine (2003), em seu prefácio à Le rêve, la transe et la folie, definiu precisamente esse pensamento ligando-o à parte maldita de Georges Bataille (2011), e a qual podemos associar a sociologia do teatro que Jean Duvignaud (1999) subintitulou pertinentemente de sociologia das sombras coletivas.

${ }^{14}$ Nessa obra, Barthes observa e descreve o Neutro "[...] não mais nos fatos da língua, mas nos fatos de discurso, subentendendo-se que essa palavra aplica todo sintagma articulado pelo sentido: textos literários, filosóficos, místicos, mas também gestos, comportamentos e condutas codificadas pela sociedade, moções internas do sujeito" (2002, p. 261) e, por fim, explica: “[...] tentamos fazer entender que o Neutro não correspondia necessariamente a imagem plana, fundamentalmente depreciada que tem dela a Doxa, mas podendo constituir um valor forte, ativo" (Barthes, 2002, p. 262). 


\section{Referências}

BARBA, Eugenio; SAVARESE, Nicola. L'Énergie qui Danse. Dictionnaire d'Anthropologie Théâtrale. Montpellier: L'Entretemps, 2008.

BARTHES, Roland. Le Neutre. Cours au Collège de France (1977-1978). Paris: Seuil/IMEC, 2002a.

BARTHES, Roland. L'Analyse Rhétorique. In: BARTHES, Roland. Oeuvres Complètes, II (1962-1967). Paris: Seuil, 2002b.

BATAILlE, Georges. La Part Maudite. Paris: Minuit, 2011.

BERGSTROM, Carl T. An Introduction to the Theory of Honest Signalling. 2001. Disponível em: <http://octavia.zoology.washington.edu/handicap/>. Acesso em: 10 set. 2009.

BHABHA, Homi K. Les Lieux de la Culture. Une théorie postcoloniale. Paris: Payot \& Rivages, 2007.

BIÃO, Armindo Jorge de Carvalho. Etnocenologia e a Cena Baiana: textos reunidos. Salvador: P\&A Grafica e Editora, 2009.

BIÃO, Armindo Jorge de Carvalho. A Presença do Corpo em Cena nos Estudos da Performance e na Etnocenologia. Revista Brasileira de Estudos da Presença, Porto Alegre, Universidade Federal do Rio Grande do Sul, v. 1, n. 2, p. 346-359, jul./dez. 2011.

BROMBERGER, Christian et al. Hommage à André Leroi-Gourhan. Terrain, Paris, n. 7, p. 61-76, out. 1986.

BOURDIEU, Pierre. Le Sens Pratique. Paris: Minuit, 1980.

BUTLER, Judith. Le Pouvoir des Mots: discours de haine et politique du performatif. Paris: Éd. Amsterdam, 2004.

DAMASIO, Antonio R. L'Erreur de Descartes: la raison des émotions. Paris: Odile Jacob, 1995.

DELEUZE, Gilles; GUATTARI, Félix. Mille Plateaux: capitalisme et schizophrénie 2. Paris: Minuit, 1980.

DELEUZE, Gilles; GUATTARI, Félix. Percept, Affect, Concept, In: DELEUZE, Gilles; GUATTARI, Félix. Qu'est-ce que la Philosophie? Paris: Minuit, 1991. P. 154-188.

DERRIDA, Jacques. L'Écrirure et la Différence. Paris: Seuil, 1967.

DUVIGNAUD, Jean. Sociologie du Théâtre: sociologie des ombres collectives. Paris: PUF, 1999.

FASSIN, Didier; MEMMI, Dominique (Org.). Le Gouvernement des Corps. Paris: EHESS, 2004.

GARRABÉ, Laure. Les Rythmes d'une Culture Populaire: les politiques du sensible dans le maracatu-de-baque-solto, Pernambuco, Brésil. 2010. Tese (Doutorado em Estética, Ciências 
e Tecnologias das Artes) - Université Paris 8, Paris, 2010.

GEERTZ, Clifford. Making Experiences, Authoring Selves, In: TURNER, Victor; BRUNER, Edward M. (Org.). The Anthropology of Experience. Urbana/Chicago: Illinois University Press, 1986. P. 373-380.

GENETTE, Gérard. L'Oeuvre de l'Art 2: la relation esthétique. Paris: Seuil, 1997.

GLISSANT, Édouard. Poétique de la Relation. Poétique III. Paris: Gallimard, 1990.

JAUSS, Hans Robert. Petite Apologie de l'Expérience Esthétique. In: JAUSS, Hans Robert. Pour une Esthétique de la Réception. Paris: Gallimard, 1978. P. 135-172.

KARSENTI, Bruno. Techniques du Corps et Normes Sociales: de Mauss à Leroi-Gourhan. Intellectica, Paris, n. 26-27, p. 227-239, 1998.

LAPLANTINE, François. Préface, In: BASTIDE, Roger. Le Rêve, la Transe et la Folie. Paris: Seuil, 2003. P. 7-18.

LAPLANTINE, François. Le Social et le Sensible: introduction à une anthropologie modale. Paris: Téraèdre, 2005.

LAPLANTINE, François. Son, Images et Langage: anthropologie esthétique et subversion. Paris: Beauchesne, 2009.

LAURENT, Pierre-Joseph. Beautés Imaginaires: anthropologie du corps et de la parenté. Bruxelles: Academia-Bruylant, 2010.

LE BRETON, David. Les Passions Ordinaires: anthropologie des émotions. Paris: Payot \& Rivages, 2004a.

LE BRETON, David. L'Interactionnisme Symbolique. Paris: PUF, 2004b.

LEROI-GOURHAN, André. L'Expérience Ethnologique. In: POIRIER, Jean (Org.). Ethnologie Générale. Paris: Gallimard, Encyclopédie de La Pléiade, 1968. P. 1816-1825.

LEROI-GOURHAN, André. Le Geste et la Parole I: technique et langage. Paris: Albin Michel, 2004a.

LEROI-GOURHAN, André. Le Geste et la Parole II: la mémoire et les rythmes. Paris: Albin Michel, 2004b.

MAUSS, Marcel. Ethnologie et Anthropologie. Paris: PUF, 2001.

MAUSS, Marcel. Manuel d'Ethnographie. Paris: Payot \& Rivage, 2002.

MESCHONNIC, Henri. Critique du Rythme: anthropologie historique du langage. Paris: Verdier, 2009.

MICHON, Pascal. Les Rythmes du Politique: démocratie et capitalisme mondialisé. Paris: Les prairies ordinaires, 2007.

MORIN, Françoise. Roger Bastide ou l'Anthropologie des Gouffres. Archives des Sciences Sociales des Religions, Paris, CNRS, n. 40, p. 99-106, jul./dez. 1975. 
NEGRI, Toni. L’Anomalie Sauvage. Puissance et Pouvoir chez Spinoza. Paris: PUF, 1982.

PRADIER, Jean-Marie. Ethnoscénologie: les incarnations de l'imaginaire, Degrés, Sémiologie du spectacle vivant 2, Bruxelles, 35 ${ }^{\text {ème }}$ année, n. 129-130, p. C1-C31, 2007.

RANCIÈrE, Jacques. Aux Bords du Politique. Paris: Gallimard, 2004.

RANCIÈRE, Jacques. Le Partage du Sensible. Paris: La Fabrique, 2000.

RANCIÈRE, Jacques. Le Spectateur Émancipé. Paris: La Fabrique, 2008.

SCHAEFFER, Jean-Marie. Adieu à l'Esthétique. Paris: PUF, 2000.

SCHAEFFER, Jean-Marie. Objets Esthétiques ?, L'Homme, Espèces d'objets, n. 170, v. 2, p. 25-45, 2004.

SCHECHNER, Richard. Performance studies. An introduction. London: Routledge, 2002.

SIMONDON, Gilbert. L'Individuation Psychique et Collective. Paris: Aubier, 1989.

STIEGLER, Bernard. Constituer l'Europe 2: le motif européen. Paris: Galilée, 2005.

Laure Garrabé é graduada em Antropologia pela Universidade Lumière Lyon 2, na França, e tem doutorado em Estética, Ciências e Tecnologias das Artes pela Universidade de Paris 8. É pesquisadora associada na Maison des Sciences de l'Homme Paris Nord. Atualmente é professora visitante no Programa de Pósgraduação em Antropologia na Universidade Federal de Santa Maria, RS. É editora da Revista Cultures-Kairós.

E-mail: laure.garrabe@gmail.com

Traduzido do original em francês pela autora e revisado por Gilberto Icle.

Recebido em novembro de 2011

Aprovado em abril de 2012 